\title{
A micro-mechanical analysis of thermo-elastic properties and local residual stresses in ductile iron based on a new anisotropic model for the graphite nodules Paper
}

Andriollo, Tito; Thorborg, Jesper; Tiedje, Niels Skat; Hattel, Jesper Henri

Published in:

Modelling and Simulation in Materials Science and Engineering

Link to article, DOI:

$10.1088 / 0965-0393 / 24 / 5 / 055012$

Publication date:

2016

Document Version

Peer reviewed version

Link back to DTU Orbit

Citation $(A P A)$ :

Andriollo, T., Thorborg, J., Tiedje, N. S., \& Hattel, J. H. (2016). A micro-mechanical analysis of thermo-elastic properties and local residual stresses in ductile iron based on a new anisotropic model for the graphite nodules: Paper. Modelling and Simulation in Materials Science and Engineering, 24(5), [055012]. https://doi.org/10.1088/0965-0393/24/5/055012

\section{General rights}

Copyright and moral rights for the publications made accessible in the public portal are retained by the authors and/or other copyright owners and it is a condition of accessing publications that users recognise and abide by the legal requirements associated with these rights.

- Users may download and print one copy of any publication from the public portal for the purpose of private study or research.

- You may not further distribute the material or use it for any profit-making activity or commercial gain

- You may freely distribute the URL identifying the publication in the public portal 


\title{
A micro-mechanical analysis of thermo-elastic properties and local residual stresses in ductile iron based on a new anisotropic model for the graphite nodules
}

Tito Andriollo ${ }^{\mathrm{a}, \mathrm{c}}$, Jesper Thorborg ${ }^{\mathrm{a}, \mathrm{b}}$, Niels Tiedje ${ }^{\mathrm{a}}$ and Jesper Hattel ${ }^{\mathrm{a}}$

${ }^{a}$ Department of Mechanical Engineering, Technical University of Denmark, DK-2800 Kgs. Lyngby, Denmark

b MAGMA GmbH, D-52072 Aachen, Germany

c Corresponding author. Address: Technical University of Denmark, Produktionstorvet, Building 425, room 125, 2800 Kgs. Lyngby, Denmark. Phone: +45 452547 22. E-mail: titoan@mek.dtu.dk

\begin{abstract}
In this paper, the thermo-elastic behavior of the graphite nodules contained in ductile iron is derived on the basis of recent transmission electron microscopy investigations of their real internal structure. The proposed model is initially validated by performing a finite element homogenization analysis to verify its consistency with the room-temperature elastic properties of ductile iron measured at the macro scale. Subsequently, it is used to investigate the formation of local residual stresses around the graphite particles by simulating the manufacturing process of a typical ferritic ductile iron grade, and the results are compared with preliminary measurements using synchrotron X-rays. Finally, the obtained accurate description of the stress \& strain field at the micro scale is used to shed light on common failure modes reported for the nodules and on some peculiar properties observed in ductile iron at both micro and macro scale.
\end{abstract}




\section{Graphical abstract}
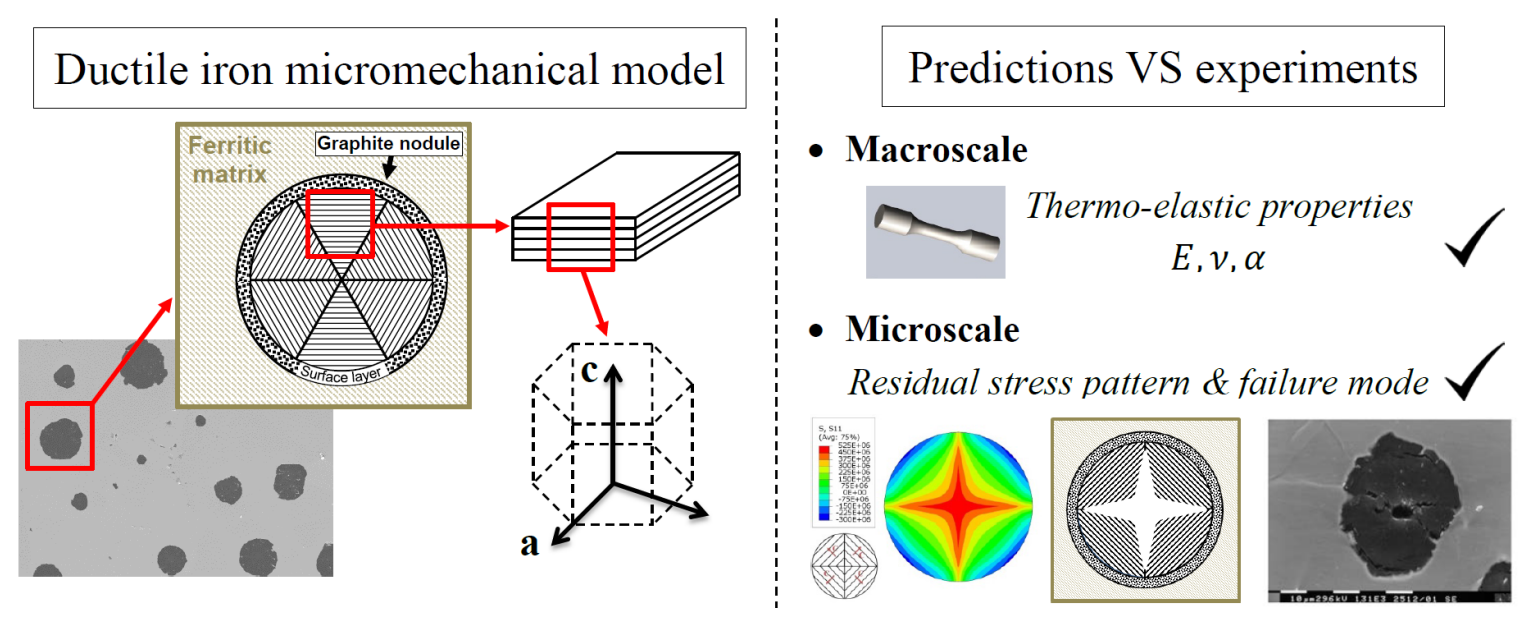

\section{Keywords}

Micromechanics; Synchrotron X-ray diffraction; Ductile iron; Anisotropic elasticity; Residual stresses; Graphite nodules

\section{Introduction}

Ductile iron represents today a modern engineering material offering a unique combination of castability, high ductility and strength at lower prices compared to traditional low carbon steels [1][2]. Its high technological importance is confirmed by recent market growth analyses [3], indicating that as many as $25 \%$ of the castings currently produced worldwide are made of ductile iron. Typical applications include small and medium sized heavily loaded parts with high demands for consistent quality for the automotive sector and very large industrial components with extreme demands for mechanical properties, particularly fatigue strength and fracture toughness [4].

From a metallurgical standpoint, ductile iron is a ternary Fe-C-Si alloy with "composite" microstructure [5][6], consisting of graphite nodules embedded in a metallic matrix which, in most engineering applications, may be either ferritic, pearlitic or a mixture of the two. The very high degree of nodularity of the secondary phase particles has justified the alternative designation of spheroidal graphite iron (SGI), to emphasize the difference with other members of the cast iron family where the graphite is present in more irregular forms. 
Despite a large number of investigations carried out in the past decades, a complete description of the mechanical behavior of the individual SGI constituents at the micro scale is still missing in the published literature [7]. This represents a major obstacle towards obtaining a thorough understanding of those properties which are intimately related to the local thermo-mechanical interactions arising among the different microstructural elements. For instance, fatigue crack propagation in the ferritic matrix has been experimentally shown to be strongly affected by the presence of the graphite particles [8], and cannot be explained on the basis of classical theoretical models which consider the material as homogeneous [9].

As discussed in [10], the lack of reliable constitutive data is more critical for the nodules rather than for the matrix, probably because their reduced size has always challenged mechanical characterization based on direct techniques. A detailed literature survey has shown that all micromechanical models for ductile iron proposed so far may be roughly listed under three different categories, according to the assumption made for the nodules' mechanical properties.

A first possibility is to simply consider the graphite particles as voids, indeed reducing SGI to a metallic material with high degree of porosity. Several researchers have followed this approach to investigate damage and ductile fracture occurring during uniaxial tensile testing, e.g. [9][11][12]. The main justification for completely neglecting the nodules in the analysis is the early debonding between the matrix and such graphitic morphologies observed already at early deformation stages on the lateral surface of a tensile test specimen. Needless to say, this assumption is not justifiable under different loading conditions, as experimental evidence exists for the capability of the nodules to oppose compressive stresses [13].

A second option, adopted by the major part of the authors, is to assume an isotropic linear elastic description of the nodules. The main problem in this case is the choice of suitable values for the elastic constants, especially Young's modulus, which is usually taken in the range 4-25 $\mathrm{GPa}$ [6]. These values are macroscopically consistent in the sense that they allow recovering the global elastic properties of ductile iron according to common micromechanical homogenization procedures [14]. Furthermore, they are also in fairly 
good agreement with nano-indentation tests [15][16] performed according to the OliverPharr method [17]. Nevertheless, the validity of such measurements is quite disputable as graphite is highly anisotropic at the nanoscale, meaning that the concept of nanoindentation based Young's modulus loses its significance. In addition, it has been argued by Bonora \& Ruggiero [18] that the sharp indenter usually employed could simply separate the graphite layers without creating any elastic deformation at all. In contrast, the latter authors have proposed much higher values, in the order of 300-375 GPa, on the basis of an inverse analysis in which the influence of the manufacturing process was taken into account for one of the very first times in literature. On the other hand, it was subsequently shown that values greater than approximately $100 \mathrm{GPa}$ are inadmissible, as the elastic properties of common grades of ductile iron cannot be retrieved due to excessive plastification of the matrix during the initial cooling stage [19][20]. Whatever the "correct" Young's modulus, the main drawback of the isotropy assumption is that it cannot be justified using elastic bound theory analysis, assuming a statistically homogeneous distribution of the graphite platelets throughout the individual nodules [10]. This means that even if the macroscopic properties may be retrieved under particular loading conditions, there is no guarantee that the predicted stress and strain fields be accurate at the micro scale.

Finally, a third group of authors have considered an elastic anisotropic description of the nodules [21][22], in an attempt to take their internal structure into account. However, the latter one was reproduced with a low fidelity level, due to the scarce experimental knowledge available at that time and the intrinsic limitations of the analytical approach adopted. As a result, the macroscopic ductile iron stiffness turned out to be over predicted. In conclusion, a reliable theoretical model for predicting the graphite particles' mechanical behavior does not seem to be currently available. Hence, it is the aim of the present paper to propose a new thermo-elastic anisotropic formulation on the basis of the most recent transmission electron microscopy investigations of the nodules' internal structure, able to provide a realistic description of the stress \& strain field existing at the microstructural level. The model is initially validated by performing a homogenization analysis to verify its consistency with the room-temperature elastic behavior of SGI at the macro scale. Subsequently, it is used to investigate the formation of local residual stresses in the ductile 
iron matrix by simulating the manufacturing process of a typical ferritic SGI grade, and the results are compared with preliminary measurements using synchrotron X-rays [23]. Last but not least, thermomechanical arguments stemming from the analysis are put forth to cast light on common failure modes reported for the nodules and on some peculiar properties observed at both the micro and macro scale.

\section{Theory}

Figure 1-a shows the microstructure of a typical grade of ferritic ductile iron, constituted by graphite nodules of high nodularity dispersed in a matrix of Si-rich ferrite. From a chemical perspective, each nodule is made of a small nucleus containing complex oxides and sulfides, which served as nucleation site during solidification [24], and a much thicker outer shell of graphitic nature, which represents the major part of the nodule by volume. As shown by electron microscopy investigations [25], the latter one, which will be the focus of the present analysis, may be schematically subdivided into two parts (figure 1-b): a bulk region, constituted by oriented graphite crystals arranged into conical sectors radiating from the nodule center to the outer periphery, and a superficial graphite layer, characterized by smaller grains with high misorientation.

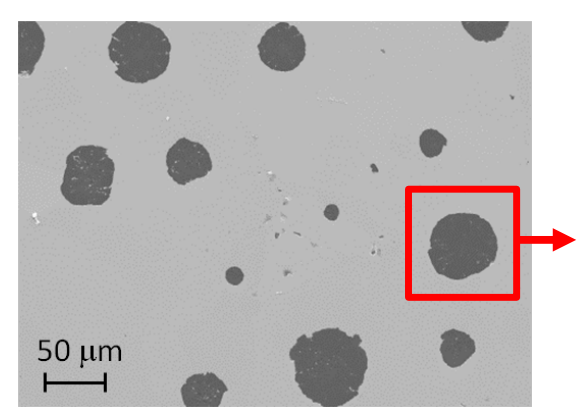

(a)

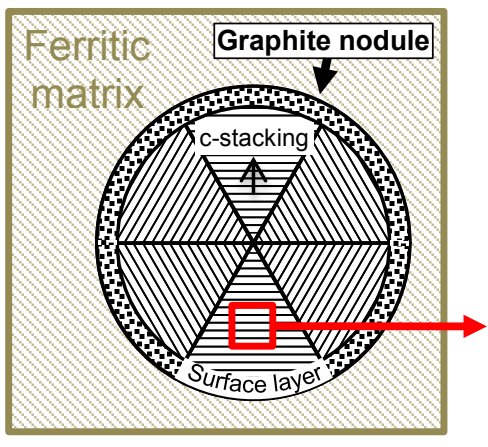

(b)

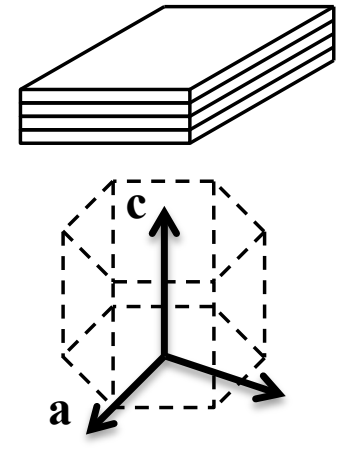

(c)

Figure 1: Nodules' structure at different scales. (a) Micrograph of ferritic ductile iron. (b) Schematic of the division of a nodule into an oriented internal bulk region and an external surface layer. (c) Platelets arrangement within a single sector and hexagonal graphite unit cell.

It seems to be well established now that the basic building blocks forming the conical sectors in the internal region are graphite platelets consisting of graphene layers piled up 
with only few crystallographic defects [26][27]. These structural units have thicknesses in the sub-micrometer range and appear to be elongated along the graphene planes. From a continuum point of view, they can be described on the basis of the hexagonal unit cell reported in figure 1-c [28], where the c-direction is orthogonal to the graphene layers. Within a sector, the platelets are stacked on each other, with the c-direction constant and oriented approximately radially. Nevertheless, the stacking is not perfect, and rotations about the c-axis occur on an almost regular basis, defining domains of similar orientation [29].

In contrast, only a few investigations have been reported in literature so far regarding the nature of the superficial structure of the nodules. Monchoux et al. [25] described a microcrystalline, highly disorientated layer approximately 1.5 micrometer thick over an overall diameter of approximately 30-40 microns, giving a powder-like diffraction diagram; later, the presence of microcrystalline areas at the extreme outer periphery of the nodules was also observed by Theuwissen et al. [30]. According to the former authors, the existence of this surface layer would be connected to the amount of graphite which precipitates during solid state cooling, due to the reduced carbon solubility in the metallic matrix. This hypothesis is also supported by the extensive work of Di Cocco et al. [31][32][33], who, in order to justify some experimental results, speculated on the existence of a gradient of mechanical properties within the nodules connected to the different stages of growth during solidification. On the basis of thermodynamic calculations, they suggested a value for the thickness of the layer associated with solid state cooling of $10 \%$ the final nodule radius, which is in very good agreement with Monchoux et al. findings. However, the reason for the different structure of the graphite crystals in this region compared to the bulk of the nodule remains unclear.

\section{Modeling and simulation}

\subsection{Nodules}

On the basis of the experimental studies presented in the previous section, a new anisotropic micromechanical model for the nodules is proposed here, which is physically consistent with their intrinsic structure. Each graphite particle is assimilated to a sphere 
composed of two concentric regions: an internal core and an external shell with thickness equal to $10 \%$ the radius. The former is additionally subdivided into a progressive number of conical sectors by means of sectioning with orthogonal planes passing through the sphere center. In this way, internal regions with 8, 48 and 80 partitions are obtained, as shown in figure 2-a, which qualitatively cover the range of values suggested by the experimental investigations. The sectors are assigned the elastic properties characteristic of rhombohedral graphite reported in table 1, as this was the graphene layer arrangement primarily observed inside the single platelets [27]. Within each conical partition, the cdirection is associated with the axis connecting the center of the sphere to the centroid of the related spherical triangle, which is formally defined as the element of the spherical surface identified by a given sector. As a body exhibiting hexagonal symmetry is transversely isotropic with respect to the basal plane (i.e. the graphene layers in this case), the other two principal material directions can be set arbitrarily without affecting the analysis. It has to be remarked that if the c-direction is prescribed parallel to the radius pointwise throughout the entire nodule core, a spherically anisotropic description is obtained, which is essentially equivalent to assuming an infinite number of conical sectors. For the external shell instead, which is supposed to be representative of the superficial layer of the nodule, a linear elastic isotropic behavior is assumed. This is motivated by the much smaller size of the crystallites in that region and their high degree of misorientation. As a consequence, the elastic properties are assumed to be equal to those of commercial grades of fine grain isotropic graphite, reported in table 2. In particular, a variation of Young's modulus between 9.7 and $10.9 \mathrm{GPa}$ is considered, associated with the uncertainty on the real size of the crystallites. Regarding Poisson's ratio, a sharp value of 0.2 is chosen instead, as preliminary investigations showed a limited influence of this quantity on the numerical results. 

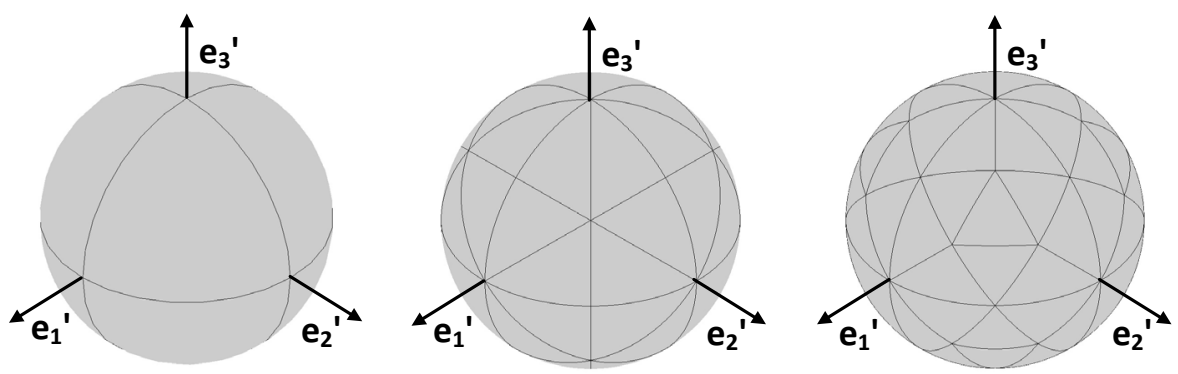

(a)

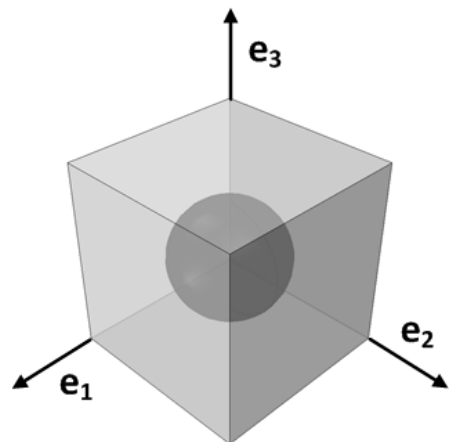

(b)

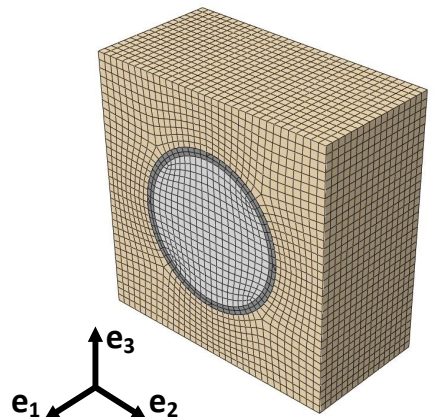

(c)

Figure 2: Micromechanical modeling. (a) Subdivision of the internal spherical nodule core region into 8, 48 and 80 sectors respectively. (b) Nodule model embedded in the 3D periodic unit cell representing the SGI microstructure. (c) Middle cross-section of a meshed unit cell in ABAQUS, assuming 8 conical sectors. The different colors of the elements represent the matrix, the nodule surface layer and the nodule core.

Table 1: Elastic constants of rhombohedral graphite [34]. Entries are in GPa.

\begin{tabular}{ccccc}
\hline $\mathrm{C} 11$ & $\mathrm{C} 44$ & $\mathrm{C} 12$ & $\mathrm{C} 13$ & $\mathrm{C} 33$ \\
\hline 1107 & 4.4 & 175 & -2.5 & 29 \\
\hline
\end{tabular}

Table 2: Physical properties of commercial grades of fine grain isotropic graphite produced by Asbury Carbons [35].

\begin{tabular}{cccc}
\hline Type & Fine Grain & Super Fine Grain & Ultra Fine Grain \\
Grade & IPG & IPG15 & IPG19 \\
Average grain size (micron) & 25 & 8 & 4 \\
Young's modulus (GPa) & 9.7 & 10.1 & 10.9 \\
Compressive strength (MPa) & 79 & 106 & 135 \\
\hline
\end{tabular}




\subsection{Ductile iron microstructure}

In order to assess the impact of the proposed model for the graphite nodules on the macroscopic elastic properties and simulate the formation of local residual stresses in the matrix, the microstructure of ductile iron is modeled using a periodic unit cell approach [36]. Therefore, a single nodule embedded in a cubic cell of ferrite is considered, as shown in figure $2-b$, whose relative size is adjusted to provide the $11.5 \%$ graphite volume fraction typical of GJS-400-15 ferritic SGI, which is taken as reference material throughout the analysis. A study similar to the one presented in [37] has shown a very limited influence of the nodule core orientation on the results (less than $1 \%$ on the calculated effective properties). As a consequence, the nodule core main axes $\boldsymbol{e}_{1}{ }^{\prime}, \boldsymbol{e}_{2}{ }^{\prime}, \boldsymbol{e}_{3}{ }^{\prime}$ visible in figure 2-a can be assumed to be aligned with the principal unit cell axes $\boldsymbol{e}_{1}, \boldsymbol{e}_{2}, \boldsymbol{e}_{3}$ without significant loss of generality.

Concerning the ferritic matrix, it is assumed to be isotropic, with Young's modulus and Poisson's ratio equal to $205 \mathrm{GPa}$ and 0.29 respectively [38]. The former value is slightly lower than that of a traditional low carbon steel, and it is due to the presence of silicon, which exerts a non-negligible effect at concentrations of a few points percent in mass [39]. An example of unit cell discretization in ABAQUS is given in figure 2-c. It has to be pointed out that more advanced methods are currently available to simulate the macroscopic behavior of materials with composite internal structure, which are primarily based on the concept of representative volume element (RVE) [40]. Nevertheless, the main disadvantage for the case at hand is that a large number of nodules with complex internal geometry should be discretized at the same time to produce a realistic RVE, making any $3 \mathrm{D}$ computation cumbersome.

\subsection{Manufacturing process}

The accurate thermomechanical analysis of all different stages involved in the manufacturing process is simplified by the fact that the particular SGI grade considered is normally used in the as-cast state, without any additional heat treatment.

Figure 3 shows a schematic of the Fe-C-Si phase diagram corresponding to a silicon concentration of $2.4 \mathrm{wt} \%$. Under the assumption of thermodynamic equilibrium, which 
suffices for the present purposes, it may be assumed that solidification of a hypereutectic melt proceeds as dictated by the red dashed arrow. The nodules form first; soon after, the eutectic reaction occurs, which leads to the formation of the austenite grains. At this point, the radius of the nodules is already equal to approximately $90 \%$ of its final value [32]. As cooling continues in the austenitic field, the nodules expand another $5 \%$, while the surrounding metallic phase undergoes thermal contraction. Nevertheless, it seems reasonable to assume that during this stage the volume mismatch is compensated by plastic flow of the soft austenitic matrix, and any tension is released almost instantaneously due to its very low flow stress, probably in the order of a few MPa [41].

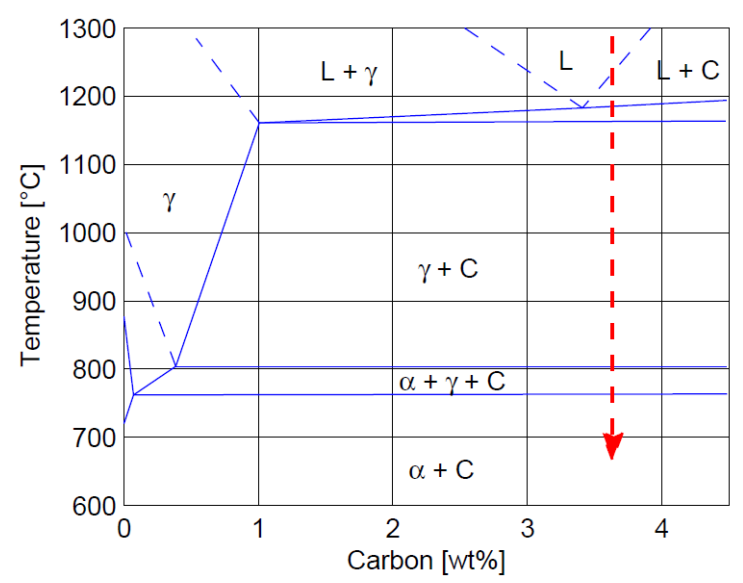

Figure 3: Schematic slice of the ternary Fe-C-Si phase diagram for a silicon concentration of $2.4 \mathrm{wt} \%$. Data taken from [42].

The situation becomes more complicated when the eutectoid interval is reached, as on the one hand the matrix transforms into ferrite, hence increasing in volume and creating more space for the graphite particles, but on the other hand the nodules expand too, due to carbon migration from the metallic phase. It is clear that modeling the complex thermo-mechanical interactions between all phases involved would in principle require simulating the nucleation and growth of the single ferritic grains. As the interest here is only in capturing the global effect, a simplified analysis is performed, as schematically shown in figure 4-a. It is assumed that the eutectoid reaction takes place simultaneously throughout the matrix at a fixed point, which may correspond to either the upper $T_{U}$ or the lower $T_{L}$ eutectoid temperature. 
In the first case, the austenite containing $0.5 \mathrm{wt} \%$ carbon transforms into supersaturated ferrite at $\mathrm{T}_{\mathrm{U}}$, with a resulting volume expansion $\Delta \mathrm{V}$. Subsequently, the ferrite gradually releases the excess of carbon until the equilibrium concentration of $0.02 \%$ is achieved at $\mathrm{T}_{\mathrm{L}}$. Meanwhile, the nodule radius increases of approximately $5 \%$, which is far more than the $\Delta \mathrm{V}$ associated with the austenite-ferrite transformation. Therefore, no "clearance" between the nodule and the matrix remains at the end of the process.

Conversely, in the second case the austenite cools down without transforming from $\mathrm{T}_{\mathrm{U}}$ to $\mathrm{T}_{\mathrm{L}}$, gradually loosing carbon. During this stage, the nodule expands to almost its final size, promoting plastic flow in the matrix. This should not look unrealistic, as Hervas et al. [13] have shown that at temperatures close to the eutectoid transformation the compressive strength of the graphite particles is much larger compared to that of the matrix. Subsequently, the low-carbon austenite transforms into ferrite at $\mathrm{T}_{\mathrm{L}}$ with an associated $\Delta \mathrm{V}$. The main difference between the two scenarios just described is that in the first one no differential expansion between the nodules and the matrix remains, whereas in the second one a differential volume change is produced. This is equal to the $\Delta \mathrm{V}$ of the austeniteferrite transformation, which, for pure iron, is of approximately $1 \%$ at $910{ }^{\circ} \mathrm{C}$ [43]. The main ductile iron allying elements, namely $\mathrm{C}$ and $\mathrm{Si}$, affect this volume variation in two ways: by increasing/decreasing the transformation temperature and by changing the lattice parameter to a different extent in the ferrite and in the austenite. As explained by Cockett and Davis [44], silicon increases the transformation temperature, therefore reducing the associated "jump" between the specific volume curves shown in figure 4-b. At the same time, it also promotes a larger lattice contraction in ferrite than in austenite: both factors contribute to reduce $\Delta \mathrm{V}$. Carbon instead generates exactly the opposite effect. Cockett and Davis measured $\Delta \mathrm{V}$ for an iron alloy with $0.005 \mathrm{wt} \% \mathrm{C}$ and increasing Si content, concluding that the primary variable controlling $\Delta \mathrm{V}$ was the transformation temperature. For instance, with $1.45 \mathrm{wt} \% \mathrm{Si}$, the phase change occurred at $1020{ }^{\circ} \mathrm{C}$ with a $\Delta \mathrm{V}$ of $0.79 \%$, which is exactly the value that may be calculated from the curves for pure iron of figure 4-b assuming the transformation to take place at the same temperature. Hence, assuming $\mathrm{T}_{\mathrm{L}}$ to be equal to $700{ }^{\circ} \mathrm{C}$ for the case at hand, $\Delta \mathrm{V}$ may be estimated as $1.4 \%$. 


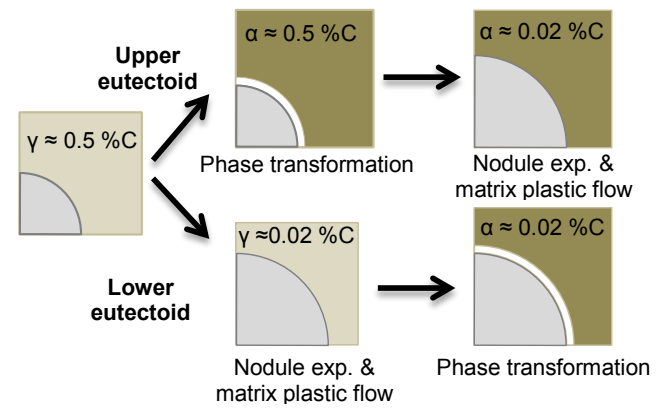

(a)

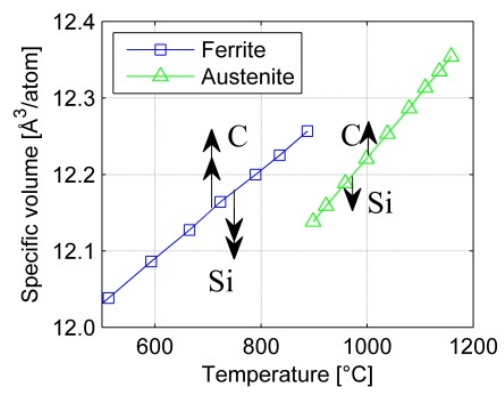

(b)

Figure 4: (a) Schematic of the volume variations occurring during the eutectoid transformation. (b) Specific volume as a function of temperature for pure iron [45], with indication of the effects of C and Si. Double arrows indicate a stronger effect compared to single arrows.

In conclusion, according to the first hypothesis no differential expansion would take place during the eutectoid transformation, whereas according to the second one the matrix would expand locally $1.4 \%$ more than the nodules in volume. As what happens in reality is probably something in between the two extremes, an average value of $0.7 \%$ is considered in the calculations.

Finally, from $700{ }^{\circ} \mathrm{C}$ down to room temperature the carbon mass contained in the nodules is assumed to remain constant. On the other hand, thermomechanical interactions with the matrix still arise from the mismatch in the values of the thermal expansion coefficient (CTE), reported in figure 5-a. Regarding this point, the data for the matrix are taken equal to those of a commercial grade of electrical steel, due to close similarities in the chemical composition [46]. As no information is available for the CTE of the nodules' surface layer, an average value among the three principal graphite directions is considered.

\subsection{Mechanical loading: elastic homogenization}

In the following, a suitable elastic homogenization procedure is described in order to verify the consistency of the proposed micromechanical model with the room-temperature behavior of ductile iron at the macro scale. Between any two equivalent points $\boldsymbol{x}$ and $\boldsymbol{x}+\boldsymbol{d}$ lying on opposite faces of the unit cell of figure 2-b and separated by the characteristic periodic length $\boldsymbol{d}$, the following periodic boundary conditions are applied:

$$
u(x+d)=u(x)+\bar{\varepsilon} \cdot d
$$




$$
t(x+d)=-t(x)
$$

where $\boldsymbol{u}$ and $\boldsymbol{t}$ denote displacement and surface traction and the $2^{\text {nd }}$ order tensor $\overline{\boldsymbol{\varepsilon}}$ represents the average of the infinitesimal strain over the entire cell volume. A detailed discussion of the implementation of the conditions (1) in the software ABAQUS is given by the authors in [37].

A linear elastic anisotropic relation between volume averages of the stress and strain fields over the unit cell is sought in the form:

$$
\overline{\boldsymbol{\sigma}}=\overline{\mathbb{C}}: \bar{\varepsilon}
$$

where $\overline{\mathbb{C}}$ is the $4^{\text {th }}$ order effective stiffness tensor. Its components are determined by prescribing in sequence six independent loadings in the form $\overline{\boldsymbol{\varepsilon}}^{(1)}, \ldots, \overline{\boldsymbol{\varepsilon}}^{(6)}$ according to expression (1), and recording the resulting average stresses $\overline{\boldsymbol{\sigma}}^{(1)}, \ldots, \overline{\boldsymbol{\sigma}}^{(6)}$. The linear system of equations generated in this way can then be solved for the effective elastic constants. Once $\overline{\mathbb{C}}$ is determined, values for the effective bulk $\bar{k}$ and shear $\bar{\mu}$ moduli are obtained as:

$$
\bar{k}=\frac{1}{3} \frac{\langle\overline{\mathbb{C}} \mid \mathbb{S}\rangle}{\langle\mathbb{S} \mid \mathbb{S}\rangle}, \quad \bar{\mu}=\frac{1}{2} \frac{\langle\overline{\mathbb{C}} \mid \mathbb{D}\rangle}{\langle\mathbb{D} \mid \mathbb{D}\rangle}
$$

where $\mathbb{S}$ and $\mathbb{D}$ are the spherical and deviatoric projection tensors [47], which form an orthogonal basis for isotropic $4^{\text {th }}$ order tensors, and $\langle\cdot \mid \cdot\rangle$ indicates the associated scalar product. Conversion to effective Young's modulus $\bar{E}$ and Poisson's ratio $\bar{v}$ is performed via the basic relations:

$$
\bar{E}=\frac{9 \bar{k} \bar{\mu}}{3 \bar{k}+\bar{\mu}}, \quad \bar{v}=\frac{3 \bar{k}-2 \bar{\mu}}{2(3 \bar{k}+\bar{\mu})}
$$

Values calculated from the latter expressions can be directly compared with those determined experimentally by means of e.g. uniaxial tensile tests, provided that the anisotropy index [14]:

$$
I_{a}=\left(\frac{\left\langle\overline{\mathbb{C}}-\overline{\mathbb{C}}^{\text {iso }} \mid \overline{\mathbb{C}}-\overline{\mathbb{C}}^{\text {iso }}\right\rangle}{\langle\overline{\mathbb{C}} \mid \overline{\mathbb{C}}\rangle}\right)^{1 / 2}, \quad \overline{\mathbb{C}}^{\text {iso }}=3 \bar{k} \mathbb{S}+2 \bar{\mu} \mathbb{D}
$$


is $\ll 1$. Among all simulations performed, the maximum recorded value of $I_{a}$ was only 1.5 $\%$. This indicates that the unit cell model is suitable to represent the well-known isotropic elastic behavior of ductile iron at the macro-scale to a sufficient degree of approximation. An important observation is to be made regarding the experimental values to be compared with those delivered by equation (4). As shown by Sjögren and Svensson [6], the graphite morphology strongly affects the macroscopic Young's modulus of SGI, meaning that a correction for the non-perfect spherical nodule shape of the material under investigation is necessary. Löhe et al. [38] thoroughly investigated this issue for grades of composition similar to the SGI considered in the present work and same graphite volume fraction, 11.5 $\%$. From their findings, it seems that a limit value of approximately $175 \pm 2 \mathrm{GPa}$ is attained for SGI with perfect spherical nodules. As this is also the value suggested in [2], it will be taken as reference value through the rest of the analysis.

\section{Results}

\subsection{Equivalent CTE for the nodules}

A preliminary set of finite element simulations have been performed considering one nodule alone, without the presence of the surrounding matrix. Figure 5-b shows numerical values for an equivalent CTE calculated on the basis of the average volume contraction during cooling according to the formula:

$$
C T E_{e q}=\frac{1}{3 V} \frac{d V}{d T}
$$

By comparing with figure 5-a, it may be noticed that the average thermal contraction of the nodule is always smaller than that of the ferritic matrix over the entire temperature range examined, independently of the number of sectors. From a physical point of view, this indicates the existence of a driving force for the formation of local residual stresses during the manufacturing process, as the free shrinkage of the ferrite is hindered by the presence of the embedded graphite particles.

In addition, it can also be observed in figure 5-b, that the larger the number of conical sectors, the smaller the corresponding equivalent CTE. This is because the graphite in the core region contracts almost only in the c-direction, which is oriented approximately 
radially. However, the contraction towards the nodule center is opposed by the high inplane stiffness of the graphite platelets with different orientation located in the neighboring sectors. Obviously, this effect becomes more pronounced when the distance between adjacent partitions is decreased, or, equivalently, the number of sectors is increased. When this number tends to infinity, the nodule core behaves as a sort of shell with high tangential stiffness, subjected to a negative internal pressure which builds up progressively as the temperature diminishes. In section 5, the consequence of this particular loading configuration will be discussed more thoroughly in relation to some experimental findings.

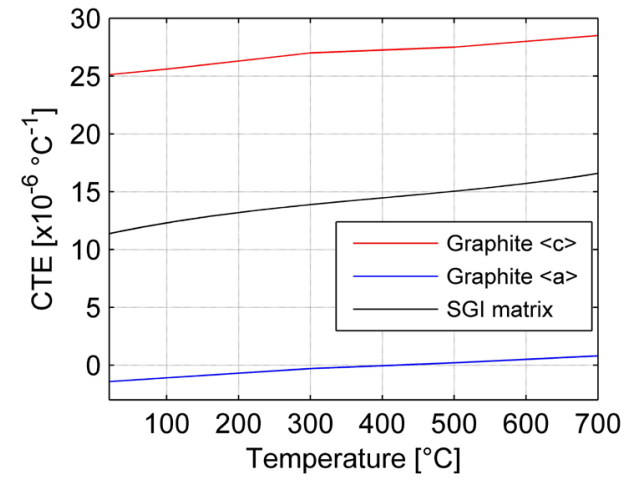

(a)

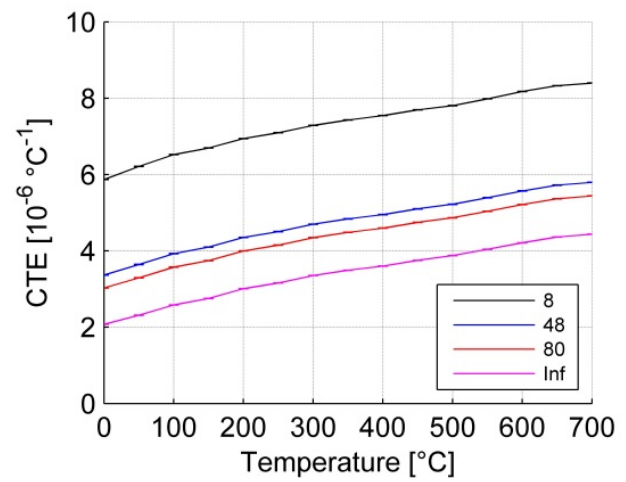

(b)

Figure 5: (a) CTE for graphite [48] and SGI matrix [49]. (b) Equivalent CTE calculated for the nodule model with different number of internal conical sectors subjected to free cooling without external matrix constraints. The error bars indicate the spread due the variation in the surface layer Young's modulus between 9.7 and $10.9 \mathrm{GPa}$. The fact that they almost collapse to a point indicates the reduced influence of the former quantity on the results.

\subsection{Thermo-elastic properties at the macro scale}

A fundamental requirement for the nodules model is the capability of providing properties at the macro scale which are in agreement with experimental measurements for ductile iron. As visible in figure 6-a and $-\mathrm{b}$, the elastic homogenization procedure of the 3D unit cell provides effective values for Young's modulus at room temperature and average CTE in the interval $700 \div 20{ }^{\circ} \mathrm{C}$ which are in excellent agreement with experiments, according to the assumed range 9.7 to $10.9 \mathrm{GPa}$ for the nodule surface layer stiffness. Within this range, it may also be seen from the error bars that a variation in the number of conical sectors from a minimum of 8 up to plus infinite produces a change in the effective Young's modulus of 2-3 GPa. This is related to the increment in the nodule core stiffness associated 
with the tendency of the graphite platelets to form a rigid shell as the number of sectors increases, as explained previously. Regarding the third and last effective isotropic thermoelastic quantity, namely Poisson's ratio, calculated values turn out to be always in the range 0.278 to 0.280 . Again, there is a very good match with experimental measurements, which have been reported between 0.275 and 0.280 according to different sources [2][50]. Finally, figure 6-c and $-d$ provide an indication of the sensitivity of the predicted effective elastic properties to variations of the surface layer thickness, for the particular choice made of the other model parameters. It is seen that in order to match the experimental Young's modulus, the former quantity has to have a value of approximately $10 \%$ the nodule radius, which is in agreement with the TEM observations and thermodynamic calculations discussed in section 2 .

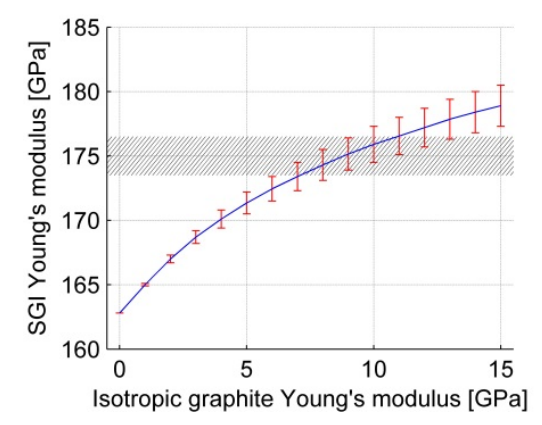

(a)

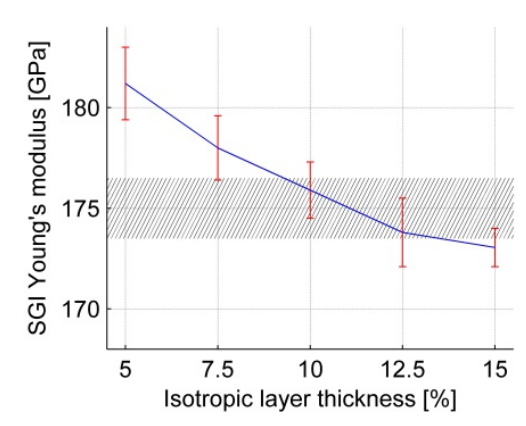

(c)

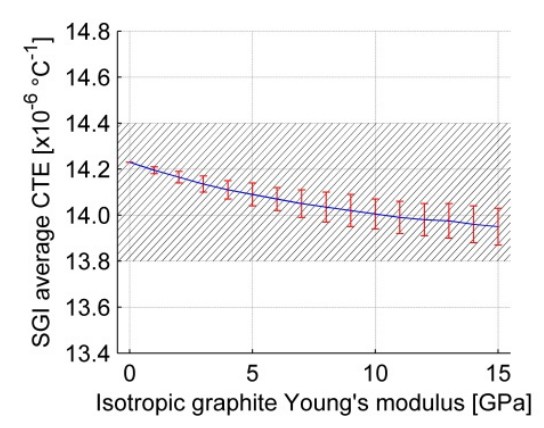

(b)

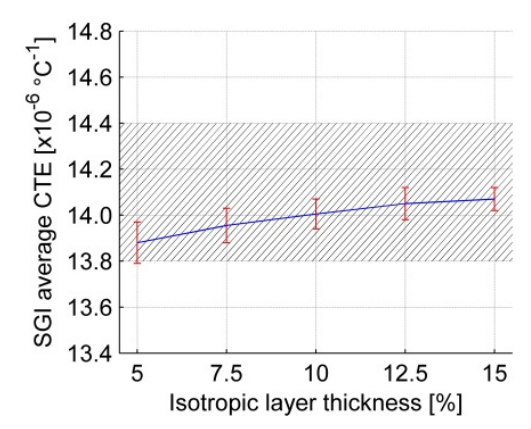

(d)

Figure 6: Effective SGI thermo-elastic properties predicted by the model, as a function of the superficial nodule layer Young's modulus $(a, b)$ and thickness $(c, d)$. In $(a, b)$ the thickness is fixed at $10 \%$ of the nodule radius, whereas in $(\mathrm{c}, \mathrm{d})$ the Young's modulus is set at $10 \mathrm{GPa}$. In all plots the error bars denote the spread due the variation in the number of conical sectors contained in the nodule core region. The hatched intervals indicate reference exp. values for the SGI grade considered; the avg. CTE interval is defined by the values given in [2] and [50]. 


\subsection{Residual stresses}

Having verified the consistency of the proposed model with the macroscopic thermo-elastic properties of ductile iron, the attention is now turned to the residual stress prediction at the microscopic scale. In general, it is observed that very large hoop stresses are generated during cooling at the extreme outer periphery of the nodule core, as visible in figure 7 , due to the high in-plane stiffness of the graphite platelets in that region, which strongly opposes the compressive action generated by the matrix. In particular, extremely high compressive stresses, above $1 \mathrm{GPa}$, are recorded at the points of contact between two or more conical sectors. These values are probably unrealistic, as local buckling and/or fracture of the single platelets are likely to occur. Nevertheless, as inelastic deformation is not considered in the present model, the stresses arising at these concentration points propagate through the nodule surface layer into the matrix. In order to diminish their unphysical impact on the overall analysis, results for the residual stresses in the matrix are presented not in terms of the maximum stress recorded, but by using an average criterion. More specifically, two average values are considered: one related to a fictitious shell enveloping the nodule and another one associated with the unit cell external boundary layer, both having a thickness of $10 \%$ the nodule radius. They are assumed to be representative of the overall stress state in the matrix regions closest to and most distant from the nodule respectively. In this way, a global indication of the residual stress gradient existing in the metallic phase of ductile iron can be obtained.

From an analysis of the related data reported in figure 8-a and -b, two major observations can be made. First of all, the mean von Mises stress is approximately one order of magnitude larger close to the nodule than at the unit cell boundary, but, at the same time, the mean hydrostatic stress shows almost negligible variations between these two different regions. The reason is that near the interface the matrix is compressed along the nodule radial direction, while it is stretched tangentially, hence generating stress components which are primarily deviatoric. Accordingly, a steep gradient in the von Mises stress is recorded. In addition, a strong influence of the nodule core partitioning is observed: it appears that by varying the number of conical sectors from 8 to 48 , a $50 \%$ increment in the 
values of both deviatoric and hydrostatic mean stresses is obtained, followed by another 50 $\%$ increase when their number tends to infinite. This effect is simply due to the increased CTE mismatch between the matrix and the nodule which arises from the reduced thermal contraction of the latter one, already pointed out in connection with figure 5 .

Finally, figure 8-c and -d show how the mean residual stresses in the matrix are affected by a variation of the graphite volume fraction within the range 7.0 to $13.0 \%$. This interval is representative of values found in typical grades of ductile iron, obtained by minor changes in the composition, solidification parameters, etc. Not surprisingly, it is seen that by increasing the nodule relative volume, the surrounding stress field increases accordingly. Nevertheless, while the other mean stress quantities almost double throughout the considered interval, the mean von Mises stress around the nodule, which is by far the most critical in terms of absolute values, exhibits only a modest $3 \%$ variation.

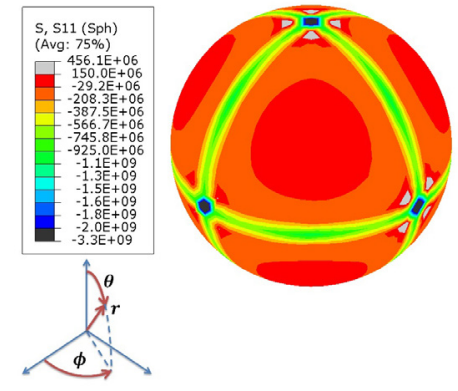

(a)

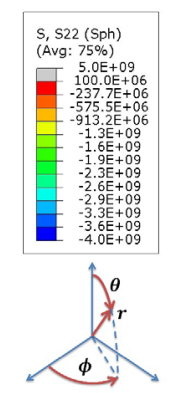

$\phi$

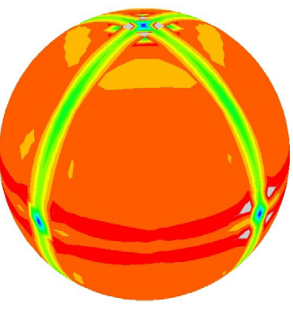

(b)

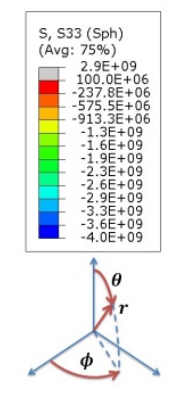

(c)

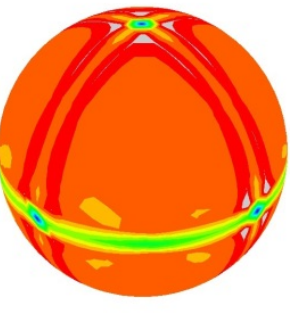

Figure 7: (a) Radial, (b) circumferential and (c) meridional residual stress components on the outer part of a nodule core with 8 internal sectors, for a surface layer Young's modulus of $10 \mathrm{GPa}$ and thickness of $10 \%$ the nodule radius. The spherical coordinate system used has the origin in the nodule center and the zenith direction points upward. Units are $\mathrm{Pa}$. The upper contour limits have been artificially reduced to avoid the spurious influence of a few elements close to the contact points between 4 sectors. 


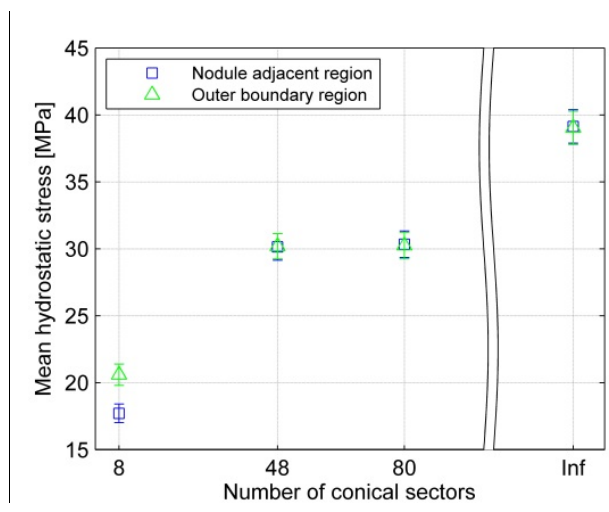

(a)

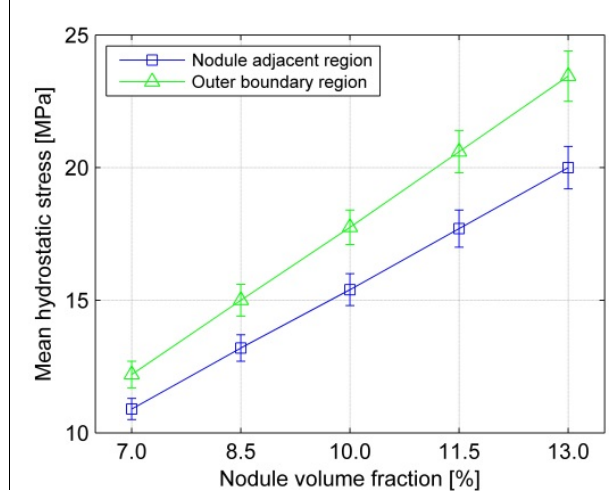

(c)

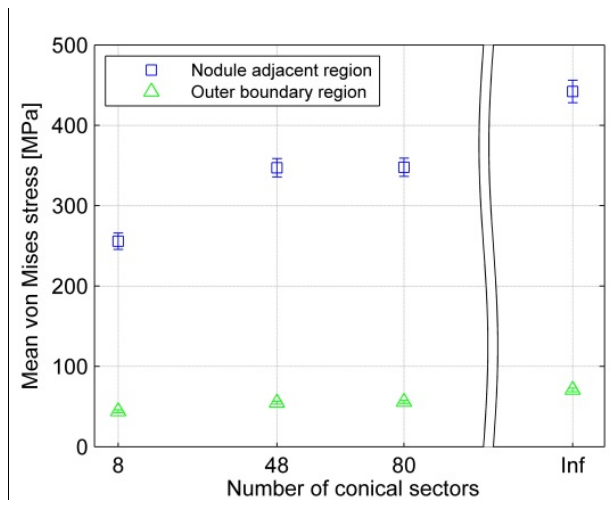

(b)

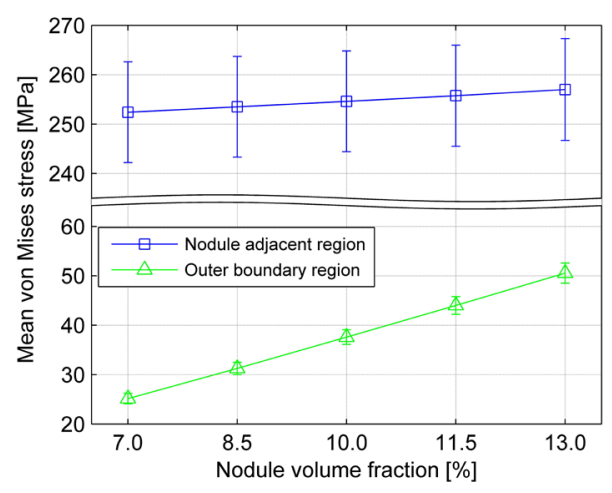

(d)

Figure 8: Mean hydrostatic and von Mises residual stresses in the matrix as a function of the number of conical sectors in the nodule core $(\mathrm{a}, \mathrm{b})$ and the graphite particles volume fraction $(\mathrm{c}, \mathrm{d})$. In $(\mathrm{a}, \mathrm{b})$ the volume fraction is $11.5 \%$, whereas in $(\mathrm{c}, \mathrm{d})$ the number of sectors is 8 . The nodule-adjacent region is identified as the matrix shell enveloping the nodule with a thickness of $10 \%$ its radius. Similarly, the outer boundary region corresponds to the $10 \%$ thick unit cell boundary layer. In all plots the error bars indicate the spread due the variation in the surface layer Young's modulus between 9.7 and $10.9 \mathrm{GPa}$.

\section{Discussion}

\subsection{Local residual elastic strains: predictions VS experiments}

The results presented in figure 8 suggest that local residual stresses of magnitudes close to the matrix yield strength might develop around the nodules during manufacturing. To verify this, experimental investigations are currently being carried out to determine the lattice parameter of the neighboring ferritic grains using the synchrotron X-rays technique described in [23], and will be presented in detail in a future work [51]. In the context of the present paper, it is important to say that a preliminary measurement of the radial residual 
elastic strain component in the matrix showed a continuous decrease in its compressive magnitude with increasing distance from the nodule, as predicted by the numerical model, even though the simulated gradients and absolute values seemed somewhat overestimated by a factor 2 .

Considering the thermo-elastic nature of the proposed anisotropic model for the nodules and the limited mechanical data available, which makes any inelastic description out of reach, the good agreement between theoretical predictions and measurements is surprisingly good. A possible explanation is that inelastic deformation does take place in the outer part of the nodule core during solid-state cooling, but it somehow remains localized to a region of limited thickness, without propagating to the entire graphite particle. In this way, the pressure exerted by the surrounding matrix is partially relieved, and the residual gradients smoothed out, but at the same time the overall material elastic stiffness remains almost unaffected. This hypothesis could justify the over prediction of the residual elastic strains, while at the same time explaining the excellent agreement obtained in terms of SGI macroscopic elastic properties (see figure 6). In addition, one should keep in mind that other important sources of error are present. In fact, a quite rough approximation of the eutectoid transformation is considered in the analysis, and any kind of high-temperature creep mechanism in the matrix, which could partly relieve the elastic strains, is ignored. Moreover, the anisotropy of the single ferritic grains is also neglected. Given the microscopic scale considered, including in the simulation some crystallographic information of the region around the nodule would probably improve the results. Finally, the periodic unit cell approach also constitutes a limitation, especially in relation to the accuracy of the calculated local stress and strain fields.

\subsection{Link with nodules failure modes}

As just mentioned, at the outer periphery of the nodules' core the predicted stress state is likely inaccurate, due to the probable occurrence of inelastic deformation. Nevertheless, outside that region the global pattern might still be quite trustworthy, at least from a qualitative point of view. Therefore, it makes sense to try to use such information to shed light on some typical failure modes observed experimentally for the graphite particles. 
In the series of works cited in section 2, Di Cocco et al. described the presence of an internal form of damage in the nodules, which was referred to as "disgregation" [33]. It was characterized by the formation of cracks originating from the center of the particles and propagating radially. The fact that this type of failure was detected during both tensile and fatigue testing suggests that it is, to a certain extent, independent of the specific loading condition applied. Rather, it could be related to the presence of a specific residual stress state in the nodules, representing the main driving force for fracture.

More specifically, it was observed during tensile testing of SGI that the nodules tend to separate from the matrix [9], hence becoming mechanically "isolated". Nevertheless, a nonnegligible stress field probably still exists inside them, associated with the anisotropic thermal deformation of the graphite occurring during manufacturing. As explained in section 4.1, the free contraction in the c-direction of the platelets located in a given sector is hindered by the presence of the adjacent partitions with different orientations. This implies that during cooling tensile stresses locally develop perpendicularly to the graphite platelets, as shown in figure 9-a. The predicted stresses are particularly high in the center of the nodule and along the interfaces between different sectors, where, additionally, a weaker mechanical bonding probably exists. It is not difficult to realize that the local change in orientation of these tensile forces could have a "tearing" action in the latter regions, at the same time promoting the formation of a "void" in the center of the particle. As long as a nodule remains fully embedded in the ferrite, the superposed compressive action of the matrix probably prevents any crack opening, but when debonding begins, the probability of having this "disgregation" mechanism increases. By comparing figure 9-b, which schematically shows the expected failure mode for a debonded particle, with figure 9-c, taken from the work of Di Cocco et al., support for the argument is found. 


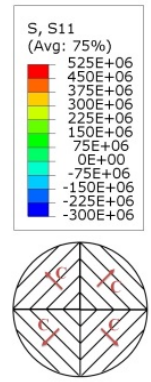

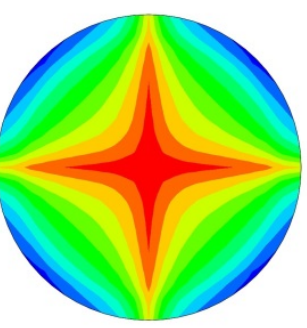

(a)

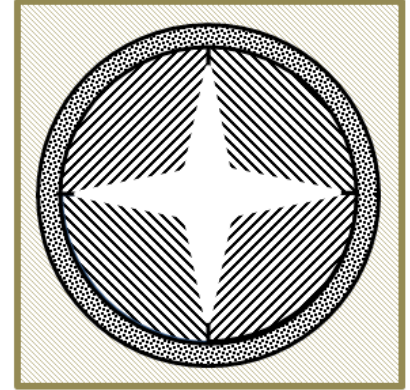

(b)

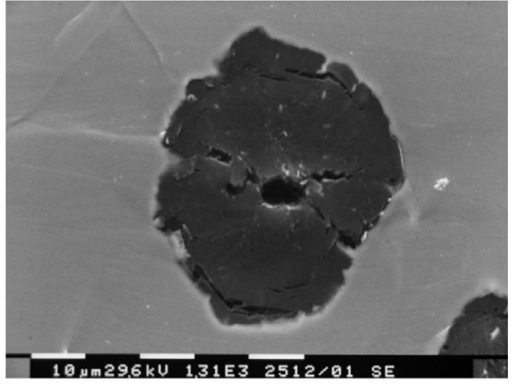

(c)

Figure 9: "Disgregation" mechanism in the bulk of a nodule. (a) Stress component locally orthogonal to the graphite platelets, over the middle section of a nodule core with 8 sectors, in $\mathrm{Pa}$, after cooling neglecting the presence of the SGI matrix. (b) Schematic of the expected failure mode. (c) Radial cracks propagating from the nodule center after tensile loading in a partially debonded nodule, reprinted from [33] with permission from Elsevier.

Another peculiar form of damage seems to be revealed by Cooper et al. [52], associated with radial cracks located on the surface of nodules which had debonded from the matrix during tensile testing. The depth of these cracks, visible in figure 10-a, was approximately of $10 \%$ the nodule radius, suggesting that they were fully localized in the microcrystalline surface layer. Figure $10-\mathrm{b}$ and $-\mathrm{c}$ present the distribution of the circumferential and meridional residual stress components on the surface of a nodule with 48 internal sectors, subjected to cooling without the presence of the surrounding matrix, to simulate the elastic deformation existing in a debonded particle at room temperature. It is seen that the stress pattern is highly affected by the partitioning of the inner core, and high tensile stresses are predicted along the continuation of the junctions between the conical sectors. Clearly, these could play an important role in the formation of the type of cracks observed in the work of the previous authors. 


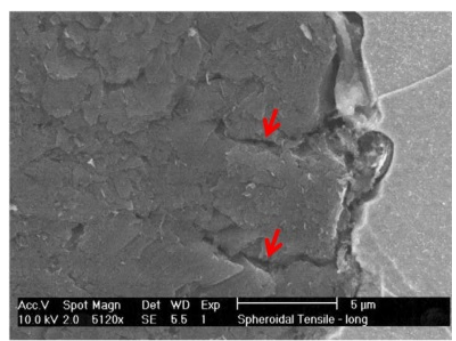

(a)

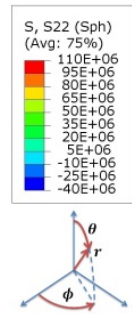

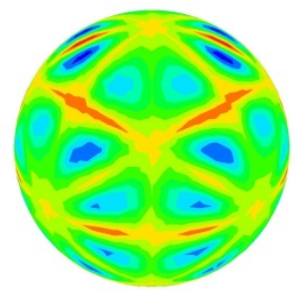

(b)
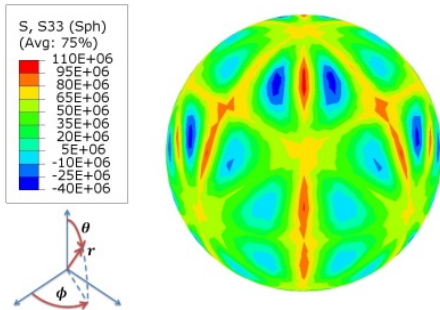

(c)

Figure 10: (a) Micrograph of the surface layer of a debonded nodule, reprinted from [52] with permission from Elsevier. The red arrows mark radial cracks. (b) Circumferential and (c) meridional normal residual stress components on the surface of a nodule with 48 internal sectors, after cooling neglecting the surrounding matrix. In (b, c) a spherical coordinate system is used, where the origin is the nodule center and the zenith direction points upward. Units are $\mathrm{Pa}$.

Finally, it should also be remarked that while performing heat treatment, Monchoux et al. [25] detected preferential radial diffusion paths in the nodule surface layer, coinciding with the continuation of the boundary between sectors. This is also in agreement with the discussion above, as areas subjected to high tensile stresses are known to favor atom diffusion.

\subsection{Potential consequences of the nodule-matrix interaction}

In this last section, the thermo-mechanical interaction arising between the nodules and the ferritic matrix during manufacturing is discussed in relation to potential changes in the material properties at both the macro and micro scale.

\subsubsection{Ductile iron mechanical performance}

The present results indicate that the graphite particles drive the formation of high deviatoric residual stresses in the surrounding matrix which strongly increase in magnitude as the number of conical sectors grows. Considering the model overestimation, discussed in section 5.1, a variation of at least $50 \mathrm{MPa}$ in their magnitude close to the nodule is expected when the number of core partitions is varied from 8 to 48 . This is approximately $1 / 3$ of the maximum stress amplitude that can be applied to the SGI grade under investigation in order to achieve a target fatigue life of 2.5 million cycles under axial loading [53]. An obvious question then arises with regard to the factors controlling such number. Intuitively, one would expect that larger nodules contain a higher number of partitions. This seems to find 
confirmation in several experimental works on the subject [27][29][30][54], where some sectors appear to branch at a certain distance from the nodule center, even though this could be an artificial effect due to sectioning of a $3 \mathrm{D}$ geometry with a plane. However, if confirmed, it would suggest the presence of a material size-effect, i.e. a non-scaling relation between particle size and magnitude of the surrounding residual stresses, which could provide additional justification for the observed link between SGI fatigue resistance and dimensions of the graphite spheroids [55][56]. Further experimental investigations would be useful to verify this potential connection and its relative importance compared to other factors.

\subsubsection{Nodules' internal structure}

During solid-state cooling the matrix exerts compressive stresses on the nodules, which can realistically be of up to $100-200 \mathrm{MPa}$. These values are not too far from the compressive strength of the isotropic graphite which the nodules' surface layer is assumed to be made of, reported in table 2. Moreover, the actual strength is probably higher, because compression tests are usually performed without lateral confining pressure, whereas in ductile iron the nodules are confined in all directions by the presence of the matrix. From this point of view, it might be that the variation in the graphite crystal structure between the surface and the bulk of the nodules be related to the increasing pressure exerted by the matrix during cooling. Oku et al. [57] investigated the effects of compressive pre-stresses on fine-grain isotropic graphite, and found that upon subsequent compression the material Young's modulus was reduced, whereas its strength was increased. The changes were more pronounced at high temperatures and were connected to rotation and cracking of the single crystallites, which tended to assume a low-energy configuration with the stiff basal planes oriented perpendicularly to the applied stress. These findings suggest that something similar could happen during the manufacturing process of ductile iron. As long as the nodules are not subjected to significant external pressure, i.e. until the end of solidification, graphite keeps growing in conical sectors. However, when tangential stresses start building up in the outer nodule layers due to contraction of the surrounding solid matrix, this growing condition is no longer energetically favorable. As a consequence, smaller 
crystallites with different orientation form, hence generating the surface layer observed by the authors cited in section 2 .

\section{Conclusions}

The present paper proposes a new thermo-elastic anisotropic micro-mechanical model for the spheroidal graphite particles contained in ductile iron. Its main features are:

- it is consistent with the most recent TEM investigations of the nodules' internal structure;

- it yields homogenized values for the ductile iron elastic properties at the macro scale in agreement with experiments;

- it describes correctly the overall local residual elastic strain pattern existing in the ferritic matrix after manufacturing, whereas absolute values seem to be somewhat over predicted, but within a factor 2 only. A reason for such overestimate is probably the inelastic deformation which is likely to occur in the outer part of the nodule internal core, due to the formation of high hoop stresses during solid-state cooling.

In addition, the proposed model seems to provide theoretical explanation for several experimental facts. First of all, it gives reason for some typical failure modes reported in literature for the graphite particles. Secondly, it predicts higher stresses in the matrix for nodules with a larger number of internal partitions. If the latter quantity were found proportional to the particles' dimension, as experiments seem to suggest, then a material size-effect would arise, which could provide additional justification for the observed link between SGI fatigue resistance and nodules' dimensions. Finally, the different graphitic structure of the superficial layer of the nodules might be explained by the observed tendency of the graphite crystallites to rotate and fragment under compressive forces, which are demonstrated to be present during solid-state cooling.

\section{Acknowledgements}

Part of this work has been supported by the Strategic Research Center "REWIND Knowledge based engineering for improved reliability of critical wind turbine 
components,' Danish Research Council for Strategic Research, grant no. 10-093966. The authors gratefully acknowledge Y. Zhang and S. Fæster (Technical University of Denmark, Department of Wind Energy) for scientific support during preparation of the manuscript.

\section{References}

[1] C. Labrecque, M. Gagne, Review ductile iron: 50 years of continuous development, Can. Metall. Q. 37 (1998) 343-378.

[2] Ductile Iron Society, Ductile Iron data for design engineers, (2013). http://www.ductile.org/ductileiron-data/ (accessed October 10, 2015).

[3] 47th Census of World Casting Production, 2013.

[4] N.S. Tiedje, Solidification, processing and properties of ductile cast iron, Mater. Sci. Technol. 26 (2010) 505-514. doi:10.1179/026708310X12668415533649.

[5] G. Grimvall, Cast Iron as a Composite: Conductivities and Elastic Properties, Adv. Mater. Res. 4-5 (1997) 31-46. doi:10.4028/www.scientific.net/AMR.4-5.31.

[6] T. Sjögren, I.L. Svensson, Modelling the effect of graphite morphology on the modulus of elasticity in cast irons, Int. J. Cast Met. Res. 17 (2004) 271-279. doi:10.1179/136404604225022694.

[7] G. Hütter, L. Zybell, M. Kuna, Micromechanisms of fracture in nodular cast iron: From experimental findings towards modeling strategies - A review, Eng. Fract. Mech. 144 (2015) 118-141. doi:10.1016/j.engfracmech.2015.06.042.

[8] D.O. Fernandino, R. Boeri, Study of the fracture of ferritic ductile cast iron under different loading conditions, Fatigue Fract. Eng. Mater. Struct. 38 (2015) 610-620. doi:10.1111/ffe.12266.

[9] M.J. Dong, B. Tie, A.S. Béranger, C. Prioul, D. François, Damage Effect on the Fracture Toughness of Nodular Cast Iron, Adv. Mater. Res. $4-5$ (1997) 181-188. doi:10.4028/www.scientific.net/AMR.45.181 .

[10] T. Andriollo, J. Hattel, On the isotropic elastic constants of graphite nodules in ductile cast iron: analytical and numerical micromechanical investigations, Mech. Mater. 96 (2016) 138-150. doi:10.1016/j.mechmat.2016.02.007.

[11] C. Berdin, M.J. Dong, C. Prioul, Local approach of damage and fracture toughness for nodular cast iron, Eng. Fract. Mech. 68 (2001) 1107-1117.

[12] D. Steglich, W. Brocks, Micromechanical modeling of damage and fracture of ductile materials, Fatigue Fract. Eng. Mater. Struct. 21 (1998) 1175-1188. doi:10.1046/j.1460-2695.1998.00078.x.

[13] I. Hervas, M.B. Bettaieb, E. Hug, Damage mechanisms evolution of ductile cast irons under thermomechanical loadings, Int. J. Mater. Prod. Technol. 47 (2013) 23. doi:10.1504/IJMPT.2013.058963.

[14] D.O. Fernandino, A.P. Cisilino, R.E. Boeri, Determination of effective elastic properties of ferritic ductile cast iron by computational homogenization, micrographs and microindentation tests, Mech. Mater. 83 (2015) 110-121. doi:10.1016/j.mechmat.2015.01.002.

[15] P. Dierickx, C. Verdu, A. Reynaud, R. Fougeres, A study of physico-chemical mechanisms responsible for damage of heat treated and as-cast ferritic spheroïdal graphite cast irons, Scr. Mater. 34 (1996) 261-268. doi:10.1016/1359-6462(95)00496-3.

[16] S.K. Pradhan, B.B. Nayak, S.S. Sahay, B.K. Mishra, Mechanical properties of graphite flakes and spherulites measured by nanoindentation, Carbon N. Y. 47 (2009) 2290-2292. doi:10.1016/j.carbon.2009.04.024.

[17] W.C. Oliver, G.M. Pharr, An improved technique for determining hardness and elastic modulus using load and displacement sensing indentation experiments, J. Mater. Res. 7 (1992) $1564-1580$.

[18] N. Bonora, A. Ruggiero, Micromechanical modeling of ductile cast iron incorporating damage. Part I: Ferritic ductile cast iron, Int. J. Solids Struct. 42 (2005) 1401-1424. doi:10.1016/j.ijsolstr.2004.07.025.

[19] T. Andriollo, J. Thorborg, N. Tiedje, J. Hattel, Modeling of damage in ductile cast iron - The effect of including plasticity in the graphite nodules, in: 14th Int. Conf. Model. Cast. Weld. Adv. Solidif. 
Process., 2015.

[20] T. Andriollo, J. Thorborg, J. Hattel, The influence of the graphite mechanical properties on the constitutive response of a ferritic ductile cast iron - A micromechanical FE analysis, in: XIII Int. Conf. Comput. Plast. Fundam. Appl., 2015.

[21] J.R. Dryden, G.R. Purdy, The effect of graphite on the mechanical properties of cast irons, Acta Metall. 37 (1989) 1999-2006. doi:10.1016/0001-6160(89)90084-9.

[22] H. Era, K. Kishitake, K. Nagai, Z.Z. Zhang, Elastic modulus and continuous yielding behaviour of ferritic spheroidal graphite cast iron, Mater. Sci. Technol. 8 (1992) 257-261. http://www.maneyonline.com/doi/abs/10.1179/mst.1992.8.3.257 (accessed May 12, 2015).

[23] W. Yang, G.E. Ice, J.D. Budai, J.Z. Tischler, B.C. Larson, Three-dimensional X-ray structural microscopy with submicrometre resolution, Nature. 415 (2002) $887-890$.

[24] D.M. Stefanescu, Cast Iron, in: Met. Handb. 9th Ed., ASM International, 1989: pp. 168-181.

[25] J.P. Monchoux, C. Verdu, G. Thollet, R. Fougères, A. Reynaud, Morphological changes of graphite spheroids during heat treatment of ductile cast irons, Acta Mater. 49 (2001) 4355-4362. doi:10.1016/S1359-6454(01)00230-0.

[26] B. Miao, K. Fang, W. Bian, G. Liu, On the microstructure of graphite spherulites in cast irons by TEM and HREM, Acta Metall. Mater. 38 (1990) 2167-2174. doi:10.1016/0956-7151(90)90084-T.

[27] B. Miao, D.O. North Wood, W. Bian, K. Fang, M.H. Fan, Structure and growth of platelets in graphite spherulites in cast iron, J. Mater. Sci. 29 (1994) 255-261. doi:10.1007/BF00356601.

[28] T. Sjogren, Influences of the graphite phase on elastic and plastic deformation behaviour of cast irons - PhD Thesis, Linköping University, 2007.

[29] K. Theuwissen, J. Lacaze, M. Véron, L. Laffont, Nano-scale orientation mapping of graphite in cast irons, Mater. Charact. 95 (2014) 187-191. doi:10.1016/j.matchar.2014.06.021.

[30] K. Theuwissen, M.-C. Lafont, L. Laffont, B. Viguier, J. Lacaze, Microstructural Characterization of Graphite Spheroids in Ductile Iron, Trans. Indian Inst. Met. 65 (2012) 627-631. doi:10.1007/s12666012-0162-5.

[31] V. Di Cocco, F. Iacoviello, M. Cavallini, Damaging micromechanisms characterization of a ferritic ductile cast iron, Eng. Fract. Mech. 77 (2010) 2016-2023. doi:10.1016/j.engfracmech.2010.03.037.

[32] V. Di Cocco, F. Iacoviello, a. Rossi, M. Cavallini, S. Natali, Graphite nodules and fatigue crack propagation micromechanisms in a ferritic ductile cast iron, Fatigue Fract. Eng. Mater. Struct. 36 (2013) 893-902. doi:10.1111/ffe.12056.

[33] V. Di Cocco, F. Iacoviello, A. Rossi, D. Iacoviello, Macro and microscopical approach to the damaging micromechanisms analysis in a ferritic ductile cast iron, Theor. Appl. Fract. Mech. 69 (2014) 26-33. doi:10.1016/j.tafmec.2013.11.003.

[34] G. Savini, Y.J. Dappe, S. Öberg, J.C. Charlier, M.I. Katsnelson, A. Fasolino, Bending modes, elastic constants and mechanical stability of graphitic systems, Carbon N. Y. 49 (2011) 62-69. doi:10.1016/j.carbon.2010.08.042.

[35] Asbury Carbons, Isotropic graphite for high strength applications, (2015). http://asbury.com (accessed December 6, 2015).

[36] A. Drago, M. Pindera, Micro-macromechanical analysis of heterogeneous materials: Macroscopically homogeneous vs periodic microstructures, Compos. Sci. Technol. 67 (2007) 1243-1263. doi:10.1016/j.compscitech.2006.02.031.

[37] T. Andriollo, J. Thorborg, J. Hattel, Modeling the elastic behavior of ductile cast iron including anisotropy in the graphite nodules, Int. J. Solids Struct. Submitt. (2016).

[38] D. Löhe, O. Vohringer, E. Macherauch, On Young's modulus of ferritic cast iron, Zeitschrift Fur Met. 74 (1983) $265-273$.

[39] S. Münstermann, Y. Feng, W. Bleck, Influencing parameters on elastic modulus of steels, Can. Metall. Q. 53 (2014) 264-273. doi:10.1179/1879139514Y.0000000127.

[40] M.G.D. Geers, V.G. Kouznetsova, W.A.M. Brekelmans, Multi-scale computational homogenization: Trends and challenges, J. Comput. Appl. Math. 234 (2010) 2175-2182. doi:10.1016/j.cam.2009.08.077.

[41] R. Kaibyshev, I. Kazakulov, Deformation Behavior of Fe-3\%Si Steel at High Temperatures, Key Eng. Mater. 171-174 (2000) 213-218. doi:10.4028/www.scientific.net/KEM.171-174.213.

[42] C. Vogel, C. Juhl, E. Maahn, Metallurgi for ingeniører, 9th ed., Polyteknisk Forlag, 2001. 
[43] T. Lyman, H.E. Boyer, P.M. Unterweiser, J.E. Foster, J.P. Hontas, H. Lawton, eds., Metals Handbook, Vol. 1: Properties and Selection of Metals, 8th ed., American Society for Metals, 1961.

[44] G.H. Cockett, Lattice expansion of Fe-Si alloys and volume change at A3 point, Iron Steel Inst. -- J. 201 (1963) $110-115$.

[45] G.H. Cockett, C.D. Davis, The lattice expansion of Fe-Si alloys and the volume change at the A3 point, J. Iron Steel Inst. 201 (1963) 110 - 115.

[46] Moses, Electrical steels: past, present and future developments, Phys. Sci. Meas. Instrumentation, Manag. Educ. IEE Proc. a. 137 (1990) 233 - 245.

[47] M. Itskov, Tensor Algebra and Tensor Analysis for Engineers, Springer Berlin Heidelberg, Berlin, Heidelberg, 2007. doi:10.1007/978-3-540-36047-6.

[48] E.G. Steward, B.P. Cook, E.A. Kellet, Dependence on temperature of the interlayer spacing in carbons of different graphitic perfection, Nature. 187 (1960) 1015 - 1016.

[49] Grain-oriented electrical steel - Technical data sheet, (2015). www.atimetals.com (accessed December 7, 2015).

[50] American Foundrymen's Society, Ductile iron handbook, 1992.

[51] Y. Zhang, T. Andriollo, et.al., Local residual stresses around individual graphite nodules in a ductile cast iron: Experimental characterization and comparison with theoretical models (in preparation), (2016).

[52] C.A. Cooper, R. Elliott, R.J. Young, Investigation of elastic property relationships for flake and spheroidal cast irons using Raman spectroscopy, Acta Mater. 50 (2002) 4037-4046. doi:10.1016/S1359-6454(02)00202-1.

[53] M. Shirani, G. Härkegård, Large scale axial fatigue testing of ductile cast iron for heavy section wind turbine components, Eng. Fail. Anal. 18 (2011) 1496-1510. doi:10.1016/j.engfailanal.2011.05.005.

[54] T. Hara, T. Kitagawa, K. Kuroki, S. Saikawa, K. Terayama, S. Ikeno, et al., Morphologies of Some Graphites in Ductile Cast Irons, Mater. Trans. 55 (2014) 1500-1505. doi:10.2320/matertrans.M2014167.

[55] M. Caldera, M. Chapetti, J.M. Massone, J.A. Sikora, Influence of nodule count on fatigue properties of ferritic thin wall ductile iron, Mater. Sci. Technol. 23 (2007) 1000-1004. doi:10.1179/174328407X185910.

[56] A. Vaško, Fatigue Properties of Synthetic Nodular Cast Irons, Key Eng. Mater. 635 (2014) 5-8. doi:10.4028/www.scientific.net/KEM.635.5.

[57] T. Oku, A. Kurumada, Y. Imamura, K. Kawamata, M. Shiraishi, Effects of prestresses on mechanical properties of isotropic graphite materials, J. Nucl. Mater. 258-263 (1998) 814-820. 